\title{
Variations in radon dosimetry under different assessment approaches in the Altamira cave
}

To cite this article before publication: Carlos Sainz et al $2020 \mathrm{~J}$. Radiol. Prot. in press https://doi.org/10.1088/1361-6498/ab6fd2

\section{Manuscript version: Accepted Manuscript}

Accepted Manuscript is "the version of the article accepted for publication including all changes made as a result of the peer review process, and which may also include the addition to the article by IOP Publishing of a header, an article ID, a cover sheet and/or an 'Accepted

Manuscript' watermark, but excluding any other editing, typesetting or other changes made by IOP Publishing and/or its licensors"

This Accepted Manuscript is @ $\mathbf{2 0 2 0}$ Society for Radiological Protection. Published on behalf of SRP by IOP Publishing Limited. All rights reserved..

During the embargo period (the 12 month period from the publication of the Version of Record of this article), the Accepted Manuscript is fully protected by copyright and cannot be reused or reposted elsewhere.

As the Version of Record of this article is going to be / has been published on a subscription basis, this Accepted Manuscript is available for reuse under a CC BY-NC-ND 3.0 licence after the 12 month embargo period.

After the embargo period, everyone is permitted to use copy and redistribute this article for non-commercial purposes only, provided that they adhere to all the terms of the licence https://creativecommons.org/licences/by-nc-nd/3.0

Although reasonable endeavours have been taken to obtain all necessary permissions from third parties to include their copyrighted content within this article, their full citation and copyright line may not be present in this Accepted Manuscript version. Before using any content from this article, please refer to the Version of Record on IOPscience once published for full citation and copyright details, as permissions will likely be required. All third party content is fully copyright protected, unless specifically stated otherwise in the figure caption in the Version of Record.

View the article online for updates and enhancements. 


\section{Variations in radon dosimetry under different assessment approaches in the Altamira cave}

Carlos Sainz ${ }^{1,2}$, Daniel Rábago ${ }^{1 *}$,Enrique Fernández ${ }^{1}$, Jorge Quindós ${ }^{1}$, Luis Quindós ${ }^{1}$, Alicia Fernández ${ }^{1}$, Ismael Fuente ${ }^{1}$, Jose Luis Arteche ${ }^{3}$, Luis Santiago Quindós ${ }^{1,2}$, Santiago Celaya ${ }^{1,2}$,

${ }^{1}$ Radon Group. University of Cantabria. C/Cardenal Herrera Oria s/n 39011, Santander, Spain

${ }^{2}$ The Cantabrian International Institute for Prehistoric Research (IIIPC)

${ }^{3}$ Spanish Meteorological Agency, AEMET

*Corresponding Author: Daniel Rábago (daniel.rabago@unican.es), C/Cardenal Herrera Oria s/n, 39011, Santander, Cantabria, Spain

\section{Abstract}

Caves' atmosphere is a special environment where it is necessary taking into account some of its characteristics to assess the radon dose. Equilibrium factor between radon and its progeny and, especially its unattached fraction are key parameters in radon dose evaluation. In order to consider the specific features of the Altamira Cave atmosphere, the radon and particles concentration has been measured. The mean annual radon concentration inside the cave over the period 2013-2019 is around $3500 \mathrm{~Bq} \mathrm{~m}^{-3}$ with an standard deviation of $1833 \mathrm{~Bq} \mathrm{~m}^{-3}$ and exhibits seasonal variations. This value surpass all international (WHO, IAEA, ICRP) upper action and reference levels (occupational and non occupational). Dose rate levels expressed in $\mu \mathrm{Sv} \mathrm{h}^{-1}$ were estimated for four different equilibrium scenarios between radon and its progenies ${ }^{218} \mathrm{Po}$, ${ }^{214} \mathrm{~Pb},{ }^{214} \mathrm{Bi}$ and ${ }^{214} \mathrm{Po}$. Newest dose conversion factors (DCF) have been used and the contribution made to the dose by the unattached fraction of radon progeny has been also assessed from the particle concentration. The results suggest that the mean annual dose levels show variations of up to $500 \%$ due to the range of the equilibrium factors $(F)$, and the unattached fraction $\left(f_{\mathrm{p}}\right)$ considered in this study. Given the high radon concentrations usually found in show caves, the best way to reduce this variability and its associated uncertainty in dose assessment is to conduct specific studies aimed to determine both the equilibrium factor and the unattached fraction of progenies.

Keywords: radon dose; progeny; dose conversion factor; cave; Altamira

\section{Introduction}

Radon gas $\left({ }^{222} \mathrm{Rn}\right)$ comes from the radioactive decay of the radium $\left({ }^{226} \mathrm{Ra}\right)$ present in varying amounts in almost all the materials of the Earth's crust (Hofmann et al., 2012; Baskaran, 2016). Its gaseous nature allows it to diffuse, whether carried by air inside the soil, or by water flowing in underground aquifers, from original source to the atmosphere, becoming a common component of the air in all the land regions of the planet (World Health Organization, 2009; ICRP, 1993). Concentrations in air may be found ranging over several orders of magnitude, with minimum values in the outside air, and increasing as the production rate and level of insulation in restricted and enclosed places (Nazaroff \&Nero, 1988). Radon is transformed, by radioactive alpha decay, into solid progeny with short half-lives, in the order of minutes and less, like ${ }^{214} \mathrm{Po}$ with $160 \mu \mathrm{s}$. The behaviour of these progeny is complex, on the one hand they can be deposited on macroscopic surfaces in the environment, or, on the other, may remain in the air. Of the fraction of progeny that are not so deposited, and remain in the air, part is attached to aerosols, and is called the attached fraction, with a wide dimensional spectrum from a few nanometres to more than a micron (Butterweck-Dempewolf et al., 1997; Reineking \& Porstendörfer, 1988), 
and on the other hand radon progeny may also be found that are not attached to aerosols, the so-called unattached fraction $\left(f_{\mathrm{p}}\right)$.

When a mixture of radon gas and its progeny is breathed in, the fact that the former is a noble gas means that only an insignificant fraction is retained in the respiratory tract. However, the solid nature of the progeny means that they remain fixed in different regions of the respiratory tract, depending on their size (Reineking \& Porstendörfer, 1988). Bearing in mind the condition of alpha emitters of some of these progeny, it can be clearly understood that it is the progeny and not the radon that are primarily responsible for irradiating the lungs (ICRP, 2017). For this reason, in order to make an appropriate estimate of the dose received by inhalation of radon and its progeny, it is essential to know both the equilibrium factor $F$, defined as the ratio between the equivalent equilibrium concentration of radon $E E C$, assessed from the concentrations of the radon progeny and of radon gas $C$, and the unattached fraction $f_{\mathrm{p}}$.

Continued inhalation of air with radon in dwellings and workplaces poses a scientifically-proven risk to health, which depends mainly on levels and duration of exposure. In 1988, the International Agency for Research on Cancer (IARC), includes radon in the main category of carcinogens, Class I as carcinogen to humans with extensive scientific backing (IARC, 1988). More recently, the World Health Organization (WHO), with the cooperation of more than a hundred scientists and experts on radon, created an international project that resulted in the publication "WHO handbook on indoor radon: a public health perspective" (World Health Organization, 2009) which brings together the main problematic aspects of radon globally. The section on health effects states that exposure to radon is the second cause of lung cancer, after smoking, in the most developed countries. More recent studies confirm the link between the exposure to radon and risk of lung cancer worldwide (Gaskin et al., 2018).

The first publication of the International Commission on Radiological Protection (ICRP) given over exclusively to protection from radon exposure was ICRP 65, published in 1993 (ICRP, 1993). A distinction was established at that time between dwellings and workplaces as sites of exposure, with clearly differentiable characteristics. This classification was maintained in successive publications about radon, until the current version ICRP 137 de 2017 (ICRP, 2017), which describes a wider range of exposure scenarios. Since 1993 the concepts of "Dose Conversion Factor" (DCF) or "Dose Coefficient" have been considered necessary to convert the levels of exposure to radon and its progeny (expressed in WLM or Bq $\mathrm{m}^{-3} \mathrm{~h}$ ) into equivalent dose values (expressed in $\mathrm{mSv}$ ), and therefore into the risk of lung cancer resulting from this exposure. These factors can be estimated in two independent ways. One is the so-called Dosimetric Approach, based on biokinetic and dosimetric models of the respiratory tract after inhaling radon progeny (Marsh et al., 2017), which is recommended by the ICRP for all radioactive elements that give rise to internal irradiation, except for radon. For the case of radon, and until the end of 2017, the ICRP recommended the epidemiological approximation based on the "Dose Conversion Conventions" which, in a simplified form, means a comparative analysis between the risk of lung cancer in populations exposed to radon, and the overall cancer risk in survivors of the atomic bombs, exposed largely to gamma radiation. Discrepancies between the factors given by the two approximations have been greatly reduced by the new revised risk coefficients set out in ICRP 115 in 2010 (ICRP, 2010; Vaillant \& Bataille, 2012). The ICRP publication of 2010 presented an update of the analysis of the epidemiological studies into risks of lung cancer from exposure to radon and its progeny in the population as a whole. The main result was to evaluate the risk factor per unit of exposure in $510^{-4} \mathrm{WLM}^{-1}$, which is nearly double the risk estimated in 1993. As a consequence of the above, the recommended DCF was changed to $12 \mathrm{mSv} \mathrm{WLM}^{-1}$ for 
workers (ICRP, 2010; Cigna, 2004). For this reason, publication 137 of the ICRP recommends, for the first time in its history, the use of dose coefficients derived from the dosimetric approximation, including radon and its progeny, in the set of radioactive elements deposited inside the organism.

It is well known that radon exposure in caves visited by tourists is a special scenario because of the characteristics of the air inside (Gillmore et al., 2000). Normally, the mean particle concentration $(Z)$ of the atmosphere inside a cave is much less than in the air outside, which leads to unattached fractions of progeny that are higher than those found in other workplaces or in dwellings (Sainz et al., 2007). Furthermore, the surface/volume ratio is usually rather low, which decreases deposition on surfaces, the main mechanism by which progeny in the air are reduced, and so increases the equilibrium factor $F$. Although the relation between $F$ and $f_{\mathrm{p}}$ is usually an inverse (Vargas et al., 2000), the DCF derived from this latter may be very high, because of the high dosimetric charge of the unattached radon progeny, sized from 1 to $10 \mathrm{~nm}$ (Porstendörfer, 2002).

The Altamira Cave is a world standard in the quantity, diversity and quality of its cave paintings, which led to its designation as a World Heritage Site by the UNESCO in 1985 (http://whc.unesco.org/en/list/310). The concentration of radon in the interior exhibits the seasonal behaviour typical of surface caves (Sainz et al., 2018; Wang et al., 2019), related to exchange of masses of air with the outside, with maximum values in winter that may reach 8000 $\mathrm{Bq} \mathrm{m}^{-3}$, and minima in the summer of $400 \mathrm{~Bq} \mathrm{~m}^{-3}$. The conservation of its cave art makes the use of forced ventilation systems to reduce these concentrations quite unfeasible, as they would seriously affect the conditions of humidity and temperature in which the paintings are preserved.

All these specific characteristics of Altamira, and the general features of most caves visited by tourists, make it necessary to develop methods for assessing personal dosimetry, to regulate exposure time as efficiently as possible. This paper sets out different methodologies for dose assessment to estimate dose received inside the Altamira Cave using yearly and monthly time scales.

\section{Materials and methods}

\subsection{Description of the Cave and sampling points}

The Altamira Cave is in the higher section of limestone hills near Santillana del Mar, on the Western coast of Cantabria (Northern Spain), at $4^{\circ} 7^{\prime} 11^{\prime \prime}$ West, $43^{\circ} 22^{\prime} 37^{\prime \prime}$ North ( $X=409289$, $Y=4803279$; UTM 30N, ETRS89). It is a shallow cave with a North-facing entrance at an altitude of $152 \mathrm{~m}$ a.s.l, with S-shaped passages and a total length of $270 \mathrm{~m}$, and the lowest point with respect to the entrance at $16 \mathrm{~m}$ (Elez et al., 2013). 


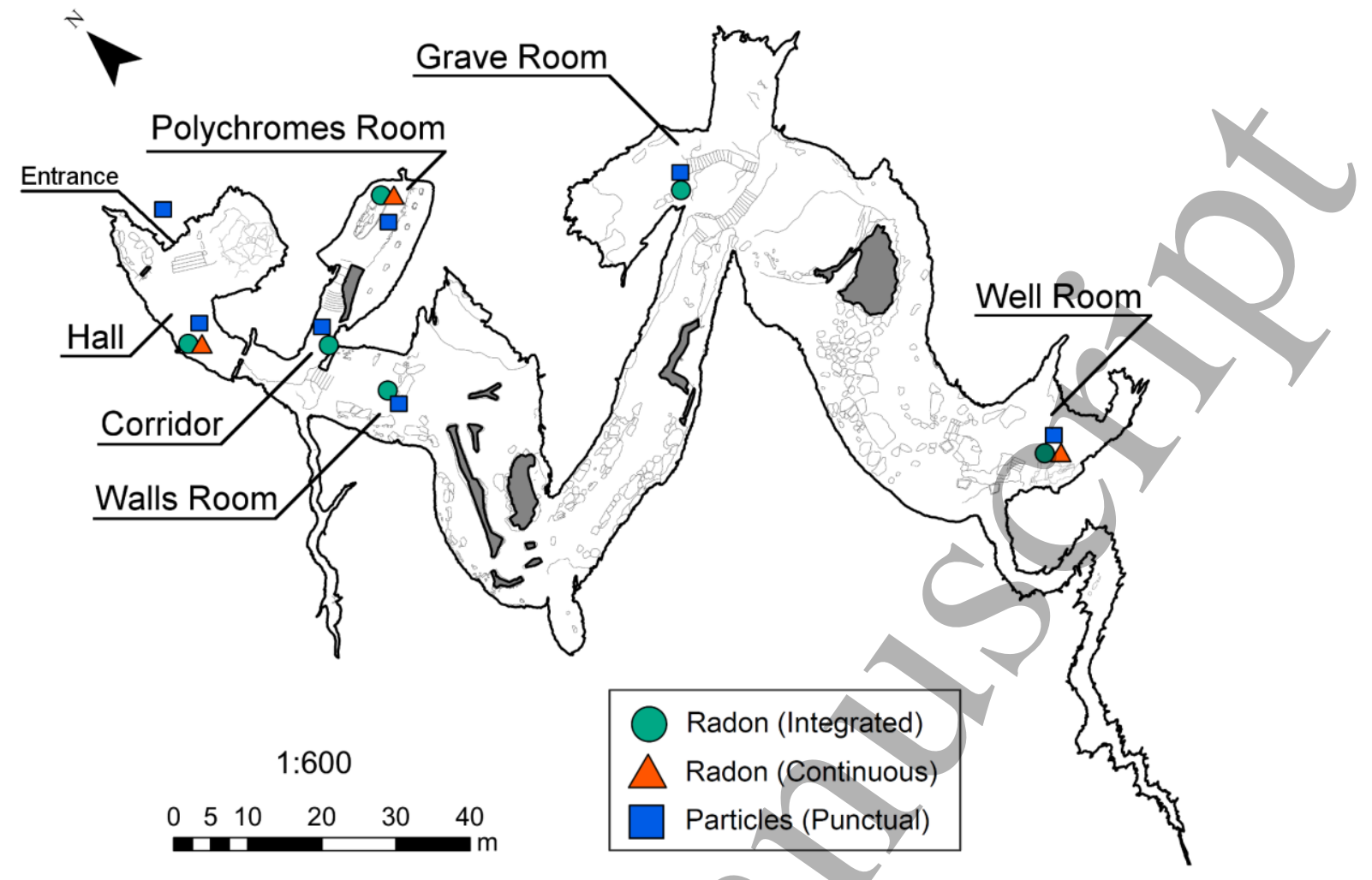

Fig. 1. Floor plan of the Altamira Cave, with the sampling points for radon and particle concentration.

\subsection{Radon gas concentration measurements}

Radon concentration in the Altamira Cave was measured in two ways. First, radon was measured at hourly intervals by continuous radon monitors in the Hall, Polychromes Room and the Well Room. Second, solid state track etched detectors CR39 were also used, giving integrated values for radon concentration over time, in the previously-mentioned rooms, and also in the Polychromes Corridor, the Walls Room and the Grave Room, as shown in Fig. 1. The locations of the detectors CR39 in the rooms were at a height above the ground of 1 meter. CR39 and radon monitors placed in the same room are close together, in order to compare results and identify any operational problems. The radon monitors and etched track detectors are replaced every two weeks.

The radon monitor used for continuous measurement is the Radon Scout (SARAD GmbH). The way they operate is based on a high-voltage chamber and a silicon detector, which the radon diffuses into. The concentration of radon is found from the energy left by the ${ }^{218}$ Po alpha particles, which adhere to the surface of the detector after radon decay due to the electric field generated in the chamber. The sensitivity of the detector is $1.8 \mathrm{cpm}$ at $1 \mathrm{kBq} \mathrm{m}^{-3}$. The range of

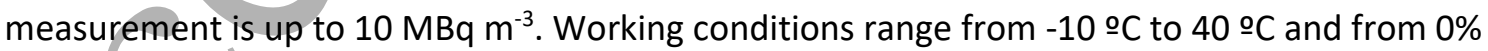
to $100 \%$ non-condensing relative humidity. The statistical uncertainty associated with this device varies from $20 \%$ to $5 \%$ in the concentration range $100-3000 \mathrm{~Bq} \mathrm{~m}^{-3}$.

There is an added difficulty associated with continuous measurement of radon concentration in environments with a high level of relative humidity, as is the case of the cave. Humidity may change the detection and gathering of progeny within the chamber (George, 1996). In order to minimise this influence, the radon monitors are placed in highly radon-permeable plastic bags, 
which allow radon to pass through but block entry of humidity to the device. Also, the monitors are replaced with others of identical characteristics every two weeks. Additionally some punctual measurements of thoron $\left({ }^{220} \mathrm{Rn}\right)$ concentration inside of the cave were performed with the Thoron Scout device (SARAD GmbH.) in the same conditions of continuous radon measurements. Results showed values below the detection limit $\left(50 \mathrm{~Bq} \mathrm{~m}^{-3}\right.$ for $1 \mathrm{~h}$ of integration time interval), so the contribution of thoron to radon measurements is considered to be negligible.

The track etched detectors used comprise a diffusion chamber and a sensor area made of CR-39 plastic, model RSKS (Radosys Ltd.). This type of passive detector measures exposure to radon, from which mean radon concentration can be found if exposure time is known. Alpha particles from the radon gas diffused into the chamber containing the detector and by the progenies generated inside, leave marks on the detector which are etched through a chemical developing process with a solution of distilled water and sodium hydroxide $(\mathrm{NaOH})$ at a concentration of $6.25 \mathrm{~mol} / \mathrm{L}$ and a temperature of $90 \stackrel{\circ}{ } \mathrm{C}$, for a period set by the manufacturer, but normally 4.5 hours. Counting of track density (tracks $/ \mathrm{mm}^{2}$ ) is done automatically with a microscope. The diffusion chamber used in this model is a conducting plastic cylinder with an effective volume of $29 \mathrm{~cm}^{3}$, which acts as a filter for radon progeny, and allows only radon gas to enter. Typical sensitivity for this kind of detector is 2.0 tracks $/ \mathrm{cm}^{2}$ for an exposure of $1 \mathrm{kBq} \mathrm{m}^{-3} \mathrm{~h}$. The uncertainty is approximately $10 \%$ for exposures in the range $500-1500 \mathrm{kBq} \mathrm{m}^{-3} \mathrm{~h}$. The calibration factor which allows conversion from track density to exposure is given by the manufacturer; however, this factor was obtained independently in the radon chamber of the Laboratory of Environmental Radioactivity of the University of Cantabria (LaRUC).

All radon concentration measurements carried out were subject to strict quality control. The LaRUC is accredited according to UNE-EN ISO/IEC 17025:2005 for measurements of radon in air, which implies a rigorous quality control of the entire measurement process, including periodic international intercomparison exercises. The radon monitors are periodically checked against a traceable international standard device in the radon chamber of LaRUC, in a stable radon atmosphere. The specifications of the chamber, the calibration procedure for the radon monitors and the assessment of their response time is analysed in detail by Fuente et al. (2018).

\subsection{Measurement of particle concentration}

Particle concentration is measured at various points both inside and outside the Altamira Cave with a period of two weeks. This parameter was measured by means of a condensation particle counter CPC TSI Model 3007 (TSI Incorporated). Air in the device is pumped at a rate of 700 $\mathrm{cm}^{3} /$ min and passes throughout a porous wick containing liquid isopropyl alcohol. The flow enters the device through a bypass in two flows, one of $100 \mathrm{~cm}^{3} / \mathrm{min}$, which is used for the analysis, while the rest $\left(600 \mathrm{~cm}^{3} / \mathrm{min}\right)$ is ignored. This flow is independent of the form of measurement chosen for the device. After exposure of the sample to the alcohol vapour, particles grow by condensation and can be detected optically with a laser light and a detection unit. This system can detect particle concentrations in the range of 0 to 100,000 particles $\mathrm{cm}^{-3}$. The measurements carried out with this condensation particle counter gives concentration in particles $/ \mathrm{cm}^{3}$ with a size below $1 \mu \mathrm{m}$ with $20 \%$ uncertainty.

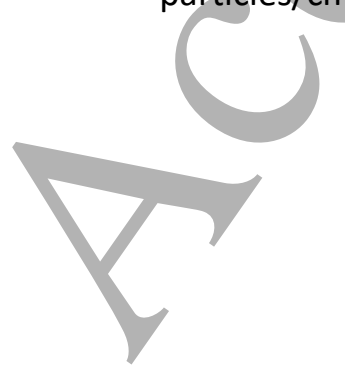




\subsection{Dose estimate}

To estimate the dose from inhalation of radon progeny it is necessary to assess exposure to radon progeny, which requires knowing the equilibrium equivalent concentration, $(E E C)$ which is that activity concentration of radon in radioactive equilibrium with its short-lived decay products that has the same potential alpha energy concentration as the non-equilibrium mixture (Hofmann et al., 2012). This magnitude, expressed in Working Level (WL), corresponds to the same potential alpha energy concentration as a mixture in equilibrium with a radon concentration of $3700 \mathrm{~Bq} \mathrm{~m}^{-3}$, and is related to the concentration of radon gas $C\left(\mathrm{~Bq} \mathrm{~m}^{-3}\right)$ via the equilibrium factor $F$ :

$$
E E C=\frac{C \cdot F}{3700}
$$

From the $E E C$ a total value for a given time period, that is, the equivalent equilibrium exposure can be $\left(E_{\text {eq }}\right)$, can be calculated, and expressed in the classic unit Working Level Month (WLM) as:

$$
E_{e q}=\frac{E E C \cdot \Delta t}{170}
$$

where $\Delta t(\mathrm{~h})$ is the exposure period considered and the value 170 correspond to the number of working hours per month considered in the original definition of WLM.

The effective dose $H(\mathrm{mSv}$ ) received over the exposure period can be calculated via the following expression:

$$
H=E_{e q} \cdot D C F
$$

where $D C F$ (mSv/WLM) is the dose conversion coefficient or factor. Combining Eq. (1) and Eq. (2), this expression can be rewritten as:

$$
H(\mu \mathrm{Sv})=1.6 \cdot 10^{-3} \cdot C \cdot D C F \cdot F \cdot \Delta t
$$

Evaluating $H$ from the mean concentration values $C$ of radon, and assuming $\Delta t=1 \mathrm{~h}$, gives mean dose rate values $\left(\mu \mathrm{Sv} \mathrm{h}^{-1}\right)$ for the different periods studied (monthly and yearly). The reason for using these units in the measurements of the dose rate is to facilitate, in terms based on the order of magnitude of the typical environmental dose rates, values that can be easily used to estimate the total dose received for cave entries which practically never exceed one hour of duration. Bearing in mind that radon concentration can be measured fairly accurately, the biggest sources of uncertainty in this evaluation are $D C F$ and $F$. To properly determine the equilibrium factor, as well to measure the activity of radon gas, it is necessary to know the activity of each of the progeny, which involves expensive equipment that is not always available. It is therefore common practice to use representative values found in the literature. In the case of caves, some review studies give frequent values $F$ between 0.2 and 0.9 (Cigna, 2004), and it is common to use the value 0.4 as recommended by ICRP 137 for caves visited by tourists (ICRP, 2017). In order to make the results more easy to compare with other studies made previously in Altamira Cave, this study will consider, for each risk assessment approximation, the values of $0.2,0.4,0.7$ and 0.9 , to cover the range of equilibrium factors described for caves in the literature. Despite there being no experimental evidence in the case of the Altamira Cave, a value between 0.7 and 0.9 could be plausible given the low levels of ventilation in the cave, especially in the autumn-winter period (Sainz et al., 2018). 
In order to illustrate the wide variation that may be found in the assessment of the dose, depending on the conversion factor chosen, this study compares two different approximations for the risk derived from exposure to radon in the Altamira Cave, using in each case the four possible values of $F$ described above.

\subsubsection{Model ICRP 137}

The most recent publication of the ICRP includes recommendations on radon and dosimetry evaluations in the dosimetric model described in the publication ICRP 66 (ICRP, 1994) for different exposure scenarios. In particular, it carries out a review of different studies of radon exposure in caves, which gives information about the most relevant parameters of the dosimetric models, such as the unattached fraction of the progeny, the equilibrium factor, the dimensional spectrum of the aerosols and the humidity conditions. In consequence, the new recommended conversion coefficient for activities in caves visited by tourists is $20 \mathrm{mSv}_{\mathrm{WLM}}^{-1}$ (ICRP, 2014; 2017).

\subsubsection{Dosimetric approximation based on unattached fraction (DAUF)}

There are many statistical applications of the dosimetric model of ICRP 66 (ICRP, 1994) to a variety of situations which take into account the characteristics of atmospheric aerosols and other factors such as the rate and type of respiration or the level of physical activity (Harrison \& Marsh, 2012), which eventually give rise to a distribution of DCF's application to each situation studied. In order to obtain a more detailed approximation of radon exposure in the Altamira Cave, concentrations of particles in the air were used to evalyate the unattached fraction of progeny. Taking the semi-empirical approximation obtained by Porstendörfer (2001) and used in prior work (Sainz et al., 2007):

$$
f_{p}=\frac{414}{Z}
$$

where $Z\left(\mathrm{~cm}^{-3}\right)$ is the concentration of particles in the air. Given that the atmosphere of the Cave of Altamira has very low concentrations of aerosols, the use in this study of Eq. 5 is limited to periods in which particle concentration is above $500 \mathrm{~cm}^{-3}$. For values of $Z$ below this value, the unattached fraction is significantly higher than 1 , which is not plausible in an atmosphere with as little ventilation as the inside of the Altamira Cave (Sainz et al., 2018). The values of $f_{p}$, can be used to evaluate the dose coefficient via the following expression (Porstendörfer, 2002):

$$
D C F(\mathrm{mSv} / \mathrm{WLM})=6.1+42 \cdot f_{p}
$$

This equation was obtained for indoor sites with a ventilation level below $0.5 \mathrm{~h}^{-1}$ and without additional aerosol sources. In this way the size of the particles is displaced towards values of 200 $\mathrm{nm}$, and there is a large number of the larger particles. The mean respiration rate is held in this case to be $0.75 \mathrm{~m}^{3} / \mathrm{h}$. The ventilation rate found for the Cave of Altamira satisfies this requirement, as can be seen in Sainz et al. (2018).

\section{Results}

\subsection{Radon and particle concentration measurements}

The dose estimations were carried out using a database of radon concentration measurements obtained by our research group from July 2013 to August 2019. This database comprises integrated monthly values in each of the rooms within the Altamira Cave, and continuous mean 
hourly values in the Hall, the Polychromes Room and the Well Room. The dose was evaluated using the Cave as a whole. This was done by considering the mean value of radon and particle concentration in each of the rooms, such as the Polychromes Room containing most of the wall paintings in the Cave, and is the centre of special attention both for tourists visiting the Cave and for those entering to perform conservation or research work.

Table 1 shows a summary of the mean monthly values for each room over the study period. It also includes the mean monthly value obtained from the average of all the rooms, considered to be representative of the inside of the Altamira Cave. These average values of the radon concentration have been evaluated from the measurements offered by the continuous monitors in the Hall, Polychromes and Well rooms, and by means of the CR-39 detectors in the rest of the rooms.

Table 1. Mean and standard deviation (SD) of the mean monthly concentrations of radon for July 2013 to August 2019 in the Polychromes Room, and in the Altamira Cave in general.

\begin{tabular}{lcccc}
\hline \multirow{2}{*}{ Month } & \multicolumn{2}{c}{ Polychromes Room } & \multicolumn{2}{c}{ Altamira Cave } \\
\cline { 2 - 5 } & Mean $\left(\mathrm{Bq} \mathrm{m}^{-3}\right)$ & $\mathrm{SD}\left(\mathrm{Bq} \mathrm{m}^{-3}\right)$ & Mean $\left(\mathrm{Bq} \mathrm{m}^{-3}\right)$ & $\mathrm{SD}\left(\mathrm{Bq} \mathrm{m}^{-3}\right)$ \\
\hline January & 5342 & 725 & 5316 & 618 \\
February & 5340 & 754 & 5230 & 527 \\
March & 5184 & 796 & 5077 & 659 \\
April & 4974 & 616 & 4872 & 626 \\
May & 4037 & 1065 & 3666 & 911 \\
June & 1431 & 483 & 1560 & 353 \\
July & 587 & 171 & 847 & 155 \\
August & 650 & 130 & 979 & 209 \\
September & 1257 & 418 & 1797 & 439 \\
October & 2469 & 749 & 3105 & 927 \\
November & 4801 & 1443 & 5015 & 886 \\
December & 5777 & 1223 & 5457 & 639 \\
\hline
\end{tabular}




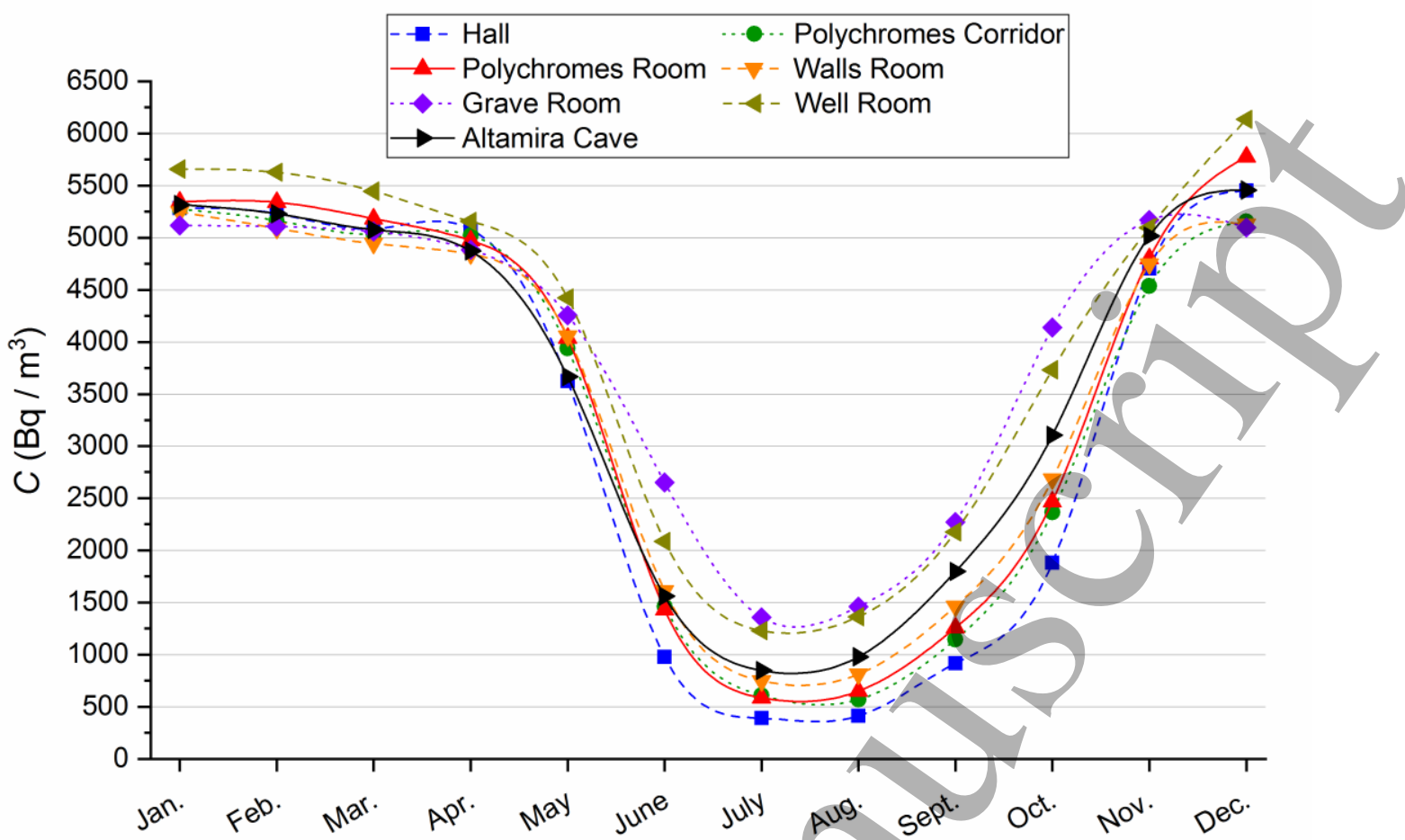

Fig. 2. Mean monthly radon concentration in each of the rooms in the Cave of Altamira using data from the period 2013-2019. It includes the average of all the rooms (black line).

The radon concentration in the various areas within the Altamira Cave in Fig. 2 exhibits seasonal variations related to the exchange of air in the Cave with that outside, mainly because of the air density gradients between the inside and the outside (Sainz et al., 2018). In the case of Altamira, the radon concentrations show minimum values during the summer, when the inside air temperature is significantly lower than outside, which produces degasifying through the porous system of cracks and fissures in the karst. On the other hand, in winter, the karstic system loses most of its permeability to gas exchange with the outside, which produces an accumulation of gases within, such as $\mathrm{CO}_{2}$ and radon. For this reason, the maximum radon concentration values in all the rooms are found during the winter months.

On the other hand, to evaluate the dose using the dosimetry model based on the unattached fraction (DAUF) the particle concentration measurements shown in Table 2 were used.

Table 2. Mean and standard deviation (SD) of the average monthly particle concentration for the period August 2013 - August 2019 in the Exterior, in the Polychromes Room and in the Cave, considering all the rooms monitored. The unattached fraction of radon progeny is calculated from Eq. (5).

\begin{tabular}{|c|c|c|c|c|c|c|c|c|c|}
\hline \multirow[b]{2}{*}{ Month } & \multicolumn{2}{|c|}{ Exterior } & \multirow[b]{2}{*}{$f_{\mathrm{p}}$} & \multicolumn{3}{|c|}{ Polychromes Room } & \multicolumn{3}{|c|}{ Altamira Cave } \\
\hline & $\begin{array}{l}\text { Mean } \\
\left(\mathrm{cm}^{-3}\right)\end{array}$ & $\begin{array}{l}\mathrm{SD} \\
\left(\mathrm{cm}^{-3}\right)\end{array}$ & & $\begin{array}{l}\text { Mean } \\
\left(\mathrm{cm}^{-3}\right)\end{array}$ & $\begin{array}{l}\text { SD } \\
\left(\mathrm{cm}^{-3}\right)\end{array}$ & $f_{\mathrm{p}}$ & $\begin{array}{l}\text { Mean } \\
\left(\mathrm{cm}^{-3}\right)\end{array}$ & $\begin{array}{l}\text { SD } \\
\left(\mathrm{cm}^{-3}\right)\end{array}$ & $f_{\mathrm{p}}$ \\
\hline January & 4435 & 2142 & 0.09 & 67 & 29 & & 136 & 60 & \\
\hline February & 2648 & 1756 & 0.16 & 94 & 62 & & 146 & 73 & \\
\hline March & 1968 & 1357 & 0.21 & 59 & 32 & & 80 & 40 & \\
\hline April & 3929 & 1985 & 0.11 & 143 & 151 & & 169 & 205 & \\
\hline May & 7013 & 4826 & 0.06 & 209 & 175 & & 293 & 325 & \\
\hline
\end{tabular}




\begin{tabular}{llllllllll} 
June & 5893 & 6223 & 0.07 & 724 & 230 & 0.57 & 807 & 245 & 0.51 \\
July & 4218 & 3571 & 0.10 & 806 & 310 & 0.51 & 833 & 371 & 0.50 \\
August & 3904 & 1621 & 0.11 & 1081 & 435 & 0.38 & 956 & 391 & 0.43 \\
September & 7313 & 6310 & 0.06 & 915 & 237 & 0.45 & 802 & 262 & 0.52 \\
October & 5003 & 2936 & 0.08 & 503 & 221 & & 430 & 155 & \\
November & 4169 & 1684 & 0.10 & 150 & 136 & & 190 & 155 & \\
December & 5260 & 1845 & 0.08 & 48 & 15 & & 99 & 93 & \\
\hline
\end{tabular}

The particle concentration values in the various rooms within the Cave shows inverse evolution over time with respect to that observed for the concentration of radon gas, as shown in Fig. 3. In general, the maximum values are reached in summer, when there is a greater exchange of gas with the outside. On the other hand, in winter the concentration of particles in suspension reaches a minimum. This behaviour is easy to understand bearing in mind that the production of particles inside the Altamira Cave is very low, and the concentrations in the air inside are always lower than in the outside air. Thus, the variations in $Z$ in each room are a complementary indicator, together with the concentration of radon or $\mathrm{CO}_{2}$, of the level of connection with the outside (Sainz et al., 2018).

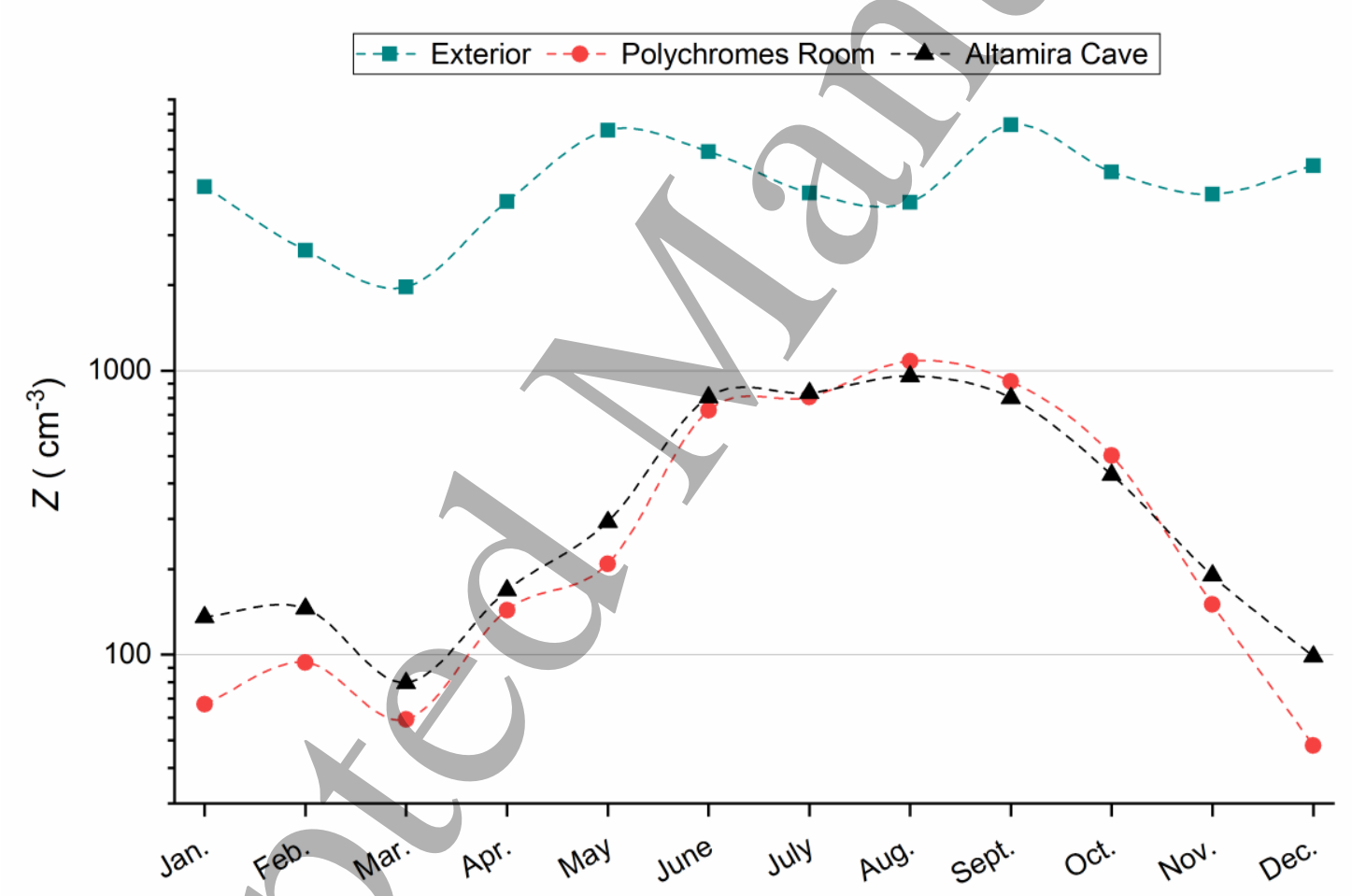

Fig. 3. Mean monthly particle concentration on the outside (outdoor air), in the Polychromes Room and in the Altamira Cave given as an average of all the rooms.

\subsection{Dose assessment}

Entrance to the Altamira Cave is carefully restricted, both to the public in general and to researchers involved in preventive conservation work on the paintings. Since 2013 guided visits by the public have been allowed on Fridays, with one or two guides passing with five visitors. During these visits, no one stays for more than 15 minutes in any room, so the doses received by the public are minimal. On the other hand, visits by researchers may be longer, and primarily 
involve the Polychromes Room, where most of the conservation effort is focused. These visits, related to sampling, recording of environmental data, state of conservation, or repair or replacement of measuring instruments, are always limited in time, by the variations of parameters like air temperature and $\mathrm{CO}_{2}$ concentration in the Polychromes Room.

Dose estimates shown in Fig. 4 have therefore been carried out on exposure periods of $\Delta t=1$ hour. The levels thus evaluated may serve as practical guidance for personal doses received by tourist guides, visitors or researchers.

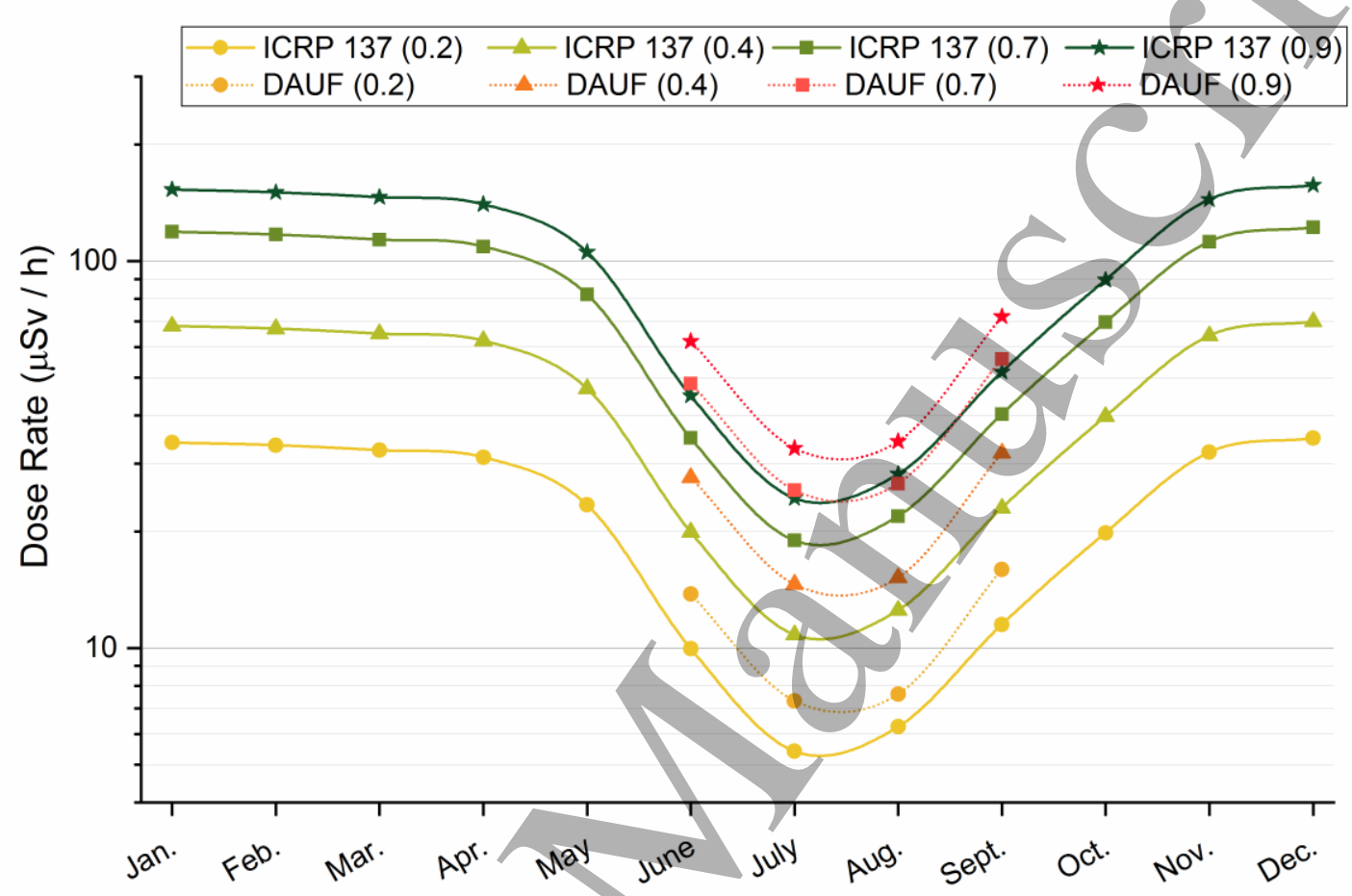

Fig. 4. Dose rate expressed in $\mu \mathrm{Sv} / \mathrm{h}$, taking into account the $D C F$ of each approximations, 20 $\mathrm{mSv} / \mathrm{WLM}$ for the ICRP137 and $6.1+42 \cdot f_{p} \mathrm{mSv} / \mathrm{WLM}$ for the DAUF, with the equilibrium factors $0.2,0.4,0.7$ and 0.9 .

Although the pattern of change over time in radon concentration is similar in all the rooms, the monthly values differ depending on the level of exchange of each room with those adjoining, and, most importantly, the degree of connection of each room with the outside. Table 3 shows the mean monthly values of the dose rate level calculated according to each of the two approximations described. It also shows the average monthly value for the Cave as a whole, and the range of variation.

Obviously, the different approximations based on ICRP137 have a constant factor, corresponding to the ratios equilibrium factors used. There is also another factor, which is variable, that it is due to the different particle concentrations recorded each month. These differences reach maxima during autumn and winter, between October and March, and minima during the summer. This is explained by the fact that the minimum values of $Z$ recorded during the period of least exchange with the outside (autumn/winter) lead to an atmosphere with a higher unattached fraction, in agreement with Eq. (5), and thus the DCF given by Eq. (6) increases significantly with respect to that found in the summer, when $Z$ is maximal, $f_{\mathrm{p}}$ is minimal. 
Table 3. Dose rate expressed in $\mu \mathrm{Sv} / \mathrm{h}$ obtained from Eq. (4) taking into account the DCF's for workers of tourist caves from the two approaches, considering the values of radon concentration and particle concentration in the Altamira Cave

\begin{tabular}{|c|c|c|c|c|c|c|c|c|}
\hline & \multicolumn{4}{|c|}{ ICRP 137} & \multicolumn{4}{|c|}{ DAUF } \\
\hline$D C F(\mathrm{mSv} / \mathrm{WLM})$ & \multicolumn{4}{|c|}{20} & \multicolumn{4}{|c|}{$6.1+42 \cdot f_{\mathrm{p}}$} \\
\hline Eq. factor $F=$ & 0.2 & 0.4 & 0.7 & 0.9 & 0.2 & 0.4 & 0.7 & 0.9 \\
\hline January & 34 & 68 & 119 & 153 & & & & \\
\hline February & 33 & 67 & 117 & 151 & & & & \\
\hline March & 32 & 65 & 114 & 146 & & & & \\
\hline April & 31 & 62 & 109 & 140 & & & & \\
\hline May & 23 & 47 & 82 & 106 & & & & \\
\hline June & 10 & 20 & 35 & 45 & 14 & 28 & 8 & 62 \\
\hline July & 5 & 11 & 19 & 24 & 7 & 15 & 26 & 33 \\
\hline August & 6 & 13 & 22 & 28 & 8 & 15 & 27 & 34 \\
\hline September & 12 & 23 & 40 & 52 & 16 & & 56 & 72 \\
\hline October & 20 & 40 & 70 & 89 & & & & \\
\hline November & 32 & 64 & 112 & 144 & & & & \\
\hline December & 35 & 70 & 122 & 157 & & & & \\
\hline Mean & 23 & 46 & 80 & 103 & & & & \\
\hline
\end{tabular}

These results can be compared, bearing in mind the natural variations of the average monthly radon concentration due to different factors, with those obtained in previous studies conducted in the Altamira Cave. In Lario et al. (2005), for a time of stay of the tourist guides of $349 \mathrm{~h}$ during one year period between 1997 and 1998, the total effective dose assuming an $F$ value of 0.7, a $D C F$ of $10 \mathrm{mSv} / \mathrm{WLM}$, and using the annual average of the radon concentration is $13.9 \mathrm{mSv}$, which would correspond to $27.8 \mathrm{mSv}$ if the DCF of the ICRP137 used in this work had been used. In our study, using the same conditions as those mentioned, we would obtain a dose rate of 80 $\mu \mathrm{Sv} / \mathrm{h}$ using the DCF of ICRP137, and $39 \mu \mathrm{Sv} / \mathrm{h}$ if DAUF approach is used. The total dose for a period of stay of 349 hours according to both approaches would be $27.6 \mathrm{mSv}$ and $13.5 \mathrm{mSv}$, respectively. It is necessary to take into account the low significance of the calculation based on the annual average of the DAUF approach, which has been done based on only four months, during which the average dose rates provided by this model have always exceeded those obtained with the approximation of the ICRP137.

\section{Conclusions}

This study provides new estimates for the radon and radon progeny dose received in the Altamira Cave. The effective doses associated with inhaling radon and its progeny have increased significantly since the first dose conversion factors were proposed in 1993. The data used come from time series of continuous measurements made over a six-year recording period. Given the regularity of seasonal and annual behaviour of radon concentration within the Cave, these estimates may be useful for future dosimetry assessments, bearing in mind the interannual variation typical of the outside weather.

As in many other tourist caves, radon concentration experiences seasonal variations that in the case of Altamira can show almost a factor of 10 between the maximum and minimum values within an annual cycle. For this reason, continuous short-term measures are essential for an accurate assessment of the dose rates received at each period of the year, allowing a more 
efficient implementation of exposure's management system than that based only on annual average values.

Despite the good agreement with previous works, obtained using annual average dose rates, this work provides a greater level of detail about the monthly variations in the dose rate due to the inhalation of radon and its progeny in the Altamira Cave, which will be very useful for the individual evaluation of the doses received by visitors, researchers and tour guides at different times of the year.

The dose level for radon exposure inside the Altamira Cave was assessed, taking into account the main factors whose variation affects this assessment. Although the minimum values, which could be easily derived from the baseline approximation of Publication 65 of the ICRP, are those currently used in Spanish law (BOE, 2001), the newest factors recommended in Publication 137 provide guidance in more accurately interpreting, with respect to current knowledge, the scale of the doses that may be received in environments like the one studied. However, another part of the Spanish law (BOE, 2012) is referred to an annual radon concentration average of 600 $\mathrm{Bq} / \mathrm{m}^{3}$ which is exceeded 6 times in this cave.

On the other hand, the estimates given here, derived from the approximation based on the relation between particle concentration and unattached fraction (DAUF), are intended as a first step towards more detailed future research into dosimetry addressing the specific conditions of radon exposure in the Altamira Cave. This approximation shows that the high concentrations of radon inside the Altamira Cave, together with the lower concentration of aerosols in suspension in the interior atmosphere, may lead to significantly higher doses than those received in other environments with similar radon levels.

In this study, we have shown that the effective dose/rate due to the inhalation of radon progenies depends strongly on the conditions of the atmosphere in which the exposure occurs. The high concentrations of radon usually present inside tourist caves make it necessary to carry out specific studies aimed at determining both the equilibrium factor and the concentration of particles in the air, in order to reduce the uncertainty in the evaluation of the received dose.

\section{Acknowledgments}

The authors are grateful to the Altamira Cave Research Centre and Museum staff for their helpful support during the sampling surveys in the cave. We also acknowledge the essential collaboration of the Spanish Meteorological Agency (AEMET).

This work was supported by the Ministry of Education, Culture and Sport of Spain (MECD) [grant number J180052] under the Project "Servicio de control y seguimiento de las condiciones ambientales y del biodeterioro de la Cueva de Altamira", and The Cantabrian International Institute for Prehistoric Research (IIIPC).

\section{References}

Baskaran, M. (2016). Radon: A tracer for geological, geophysical and geochemical studies. Basel: Springer. https://doi.org/10.1007/978-3-319-21329-3

BOE (2001). Real Decreto 783/2001, de 6 de julio, por el que se aprueba el Reglamento sobre protección sanitaria contra radiaciones ionizantes. Boletín Oficial del Estado (BOE), 178, 2728427393. https://www.boe.es/eli/es/rd/2001/07/06/783 
BOE (2012). Instrucción IS-33, de 21 de diciembre de 2011, del Consejo de Seguridad Nuclear, sobre criterios radiológicos para la protección frente a la exposición a la radiación natural. $\begin{array}{lllll}\text { Boletín Oficial del Estado (BOE), } 22 & \text { (III), 6833-6838. }\end{array}$ https://www.boe.es/eli/es/ins/2011/12/21/is33

Butterweck-Dempewolf, G., Shuler, C., \& Vezzu, G. (1997, June). Size distribution of the unattached fraction of radon progeny. In European Conference on Protection against Radon at Home and at Work. Praha, Czech Republic.

Cigna, A. A. (2004). The distribution of radon concentration in caves. International Journal of Speleology, 32(1), 8. http://dx.doi.org/10.5038/1827-806X.32.1.8

Elez, J., Cuezva, S., Fernandez-Cortes, A., Garcia-Antón, E., Benavente, D., Cañaveras, J. C., \& Sánchez-Moral, S. (2013). A GIS-based methodology to quantitatively define an Adjacent Protected Area in a shallow karst cavity: The case of Altamira cave. Journal of environmental management, 118, 122-134. https://doi.org/10.1016/i.jenvman.2013.01.020

Fuente, M., Rabago, D., Herrera, S., Quindos, L., Fuente, I., Foley, M., \& Sainz, C. (2018). Performance of radon monitors in a purpose-built radon chamber. Journal of Radiological Protection, 38(3), 1111. https://doi.org/10.1088/1361-6498/aad969

Gaskin, J., Coyle, D., Whyte, J., \& Krewksi, D. (2018). Global estimate of lung cancer mortality attributable to residential radon. Environmental health perspectives, 126(5), 057009. https://doi.org/10.1289/EHP2503

Gillmore, G. K., Sperrin, M., Phillips, P., \& Denman, A. (2000). Radon hazards, geology, and exposure of cave users: a case study and some theoretical perspectives. Ecotoxicology and Environmental Safety, 46(3), 279-288. https://doi.org/10.1006/eesa.2000.1922

George, A. C. (1996). State-of-the-art instruments for measuring radon/thoron and their progeny in dwellings-a review. Health Physics, 70(4), 451-463. 10.1097/00004032-199604000$\underline{00001}$

Harrison, J. D., \& Marsh, J. W. (2012). Effective dose from inhaled radon and its progeny. Annals of the ICRP, 41(3-4), 378-388. https://doi.org/10.1016/j.icrp.2012.06.012

Hofmann, W., Arvela, H. S., Harley, N. H., Marsh, J. W., McLaughlin, J., Röttger, A., \& Tokonami, S. (2012). 4. Characteristics and Behavior of Radon and Radon Progeny. Journal of the ICRU, 12(2), 55-70. https://doi.org/10.1093/jicru/ndv007

IARC (1988). IARC monographs on the evaluation of carcinogenic risks to humans, Man-made Mineral Fibres and Radon, 43. Lyon: France.

ICRP (1994). Human Respiratory Tract Model for Radiological Protection. ICRP Publication 66. Ann. ICRP 24 (1-3).

ICRP (1993). Protection against Radon-222 at Home and at Work. ICRP Publication 65. Ann. ICRP 23 (2). https://doi.org/10.1080/09553009414551371

ICRP (2010). Lung Cancer Risk from Radon and Progeny and Statement on Radon. ICRP Publication 115, Ann. ICRP 40(1). https://doi.org/10.1016/j.icrp.2011.08.011

ICRP (2014). Radiological Protection against Radon Exposure. ICRP Publication 126. Ann. ICRP 43(3). https://doi.org/10.1177/0146645314542212 
ICRP (2017). Occupational intakes of radionuclides: Part 3. ICRP Publication 137. Ann. ICRP 46(3/4). https://doi.org/10.1177/0146645317734963

Lario, J., Sánchez-Moral, S., Cañaveras, J. C., Cuezva, S., \& Soler, V. (2005). Radon continuous monitoring in Altamira Cave (northern Spain) to assess user's annual effective dose. Journal of Environmental Radioactivity, 80(2), 161-174. https://doi.org/10.1016/i.jenvrad.2004.06.007

Marsh, J. W., Laurier, D., \& Tirmarche, M. (2017). Radon dosimetry for workers: ICRP's approach. Radiation protection dosimetry, 177(4), 466-474. https://doi.org/10.1093/rpd/ncx065

Nazaroff, W. W., \& Nero Jr, A. V. (1988). Radon and its decay products in indoor air. New York NY, Wiley and Sons.

Porstendörfer, J. (2001). Physical parameters and dose factors of the radon and thoron decay products. Radiation Protection Dosimetry, 94(4),

365-373.

https://doi.org/10.1093/oxfordjournals.rpd.a006512

Porstendörfer, J. (2002, February). Influence of physical parameters on doses from radon exposures. In International Congress Series (Vol. 1225, pp. 149-160). Elsevier. https://doi.org/10.1016/S0531-5131(01)00510-6

Reineking, A. K. H. J., Becker, K. H., \& Porstendörfer, J. (1988). Measurements of activity size distributions of the short-lived radon progeny in the indoor and outdoor environment. Radiation Protection Dosimetry, 24(1-4), 245-250. https://doi.org/10.1093/oxfordjournals.rpd.a080279

Reineking, A., \& Porstendörfer, J. (1988). Activity size distributions of the shortlived radon decay products and their influence on the deposition probability in the human lung. Journal of Aerosol Science, 19(7), 1331-1337. https://doi,org/10.1016/0021-8502(88)90167-X

Sainz, C., Quindós, L. S., Fuente, I., Nicolás, J., \& Quindós, L. (2007). Analysis of the main factors affecting the evaluation of the radon dose in workplaces: the case of tourist caves. Journal of hazardous materials, 145(3), 368-371. https://doi.org/10.1016/i.jhazmat.2006.11.033

Sainz, C., Rábago, D., Celaya, S., Fernández,E., Quindós, J., Quindós, L., Fernández, A., Fuente, I., Arteche, J.L. \& Quindós, L. S. (2018). Continuous monitoring of radon gas as a tool to understand air dynamics in the cave of Altamira (Cantabria, Spain). Science of the total environment, 624, 416-423. https://doi.org/10.1016/j.scitotenv.2017.12.146

Vaillant, L., \& Bataille, C. (2012). Management of radon: a review of ICRP recommendations. Journal of radiological protection, 32(3), R1. http://dx.doi.org/10.1088/0952-4746/32/3/R1

Vargas, A., Ortega, X., \& Porta, M. (2000). Dose conversion factor for radon concentration in indoor environments using a new equation for the F-fP correlation. Health physics, 78(1), 80-85. 10.1097/00004032-200001000-00013

Wang, Y., Luo, W., Zeng, G., Wang, Y., Yang, H., Wang, M., Zhang, L., Cai, X., Chen, J., Cheng, A. \& Wang, S. (2019). High 222Rn concentrations and dynamics in Shawan Cave, southwest $\begin{array}{llll}\text { China. Journal of environmental 16-24. } & \text { radioactivity, 199, }\end{array}$ https://doi.org/10.1016/j.jenvrad.2018.12.029

World Health Organization (2009). WHO handbook on indoor radon: a public health perspective. Geneva: World Health Organization. https://apps.who.int/iris/handle/10665/44149 